\title{
Comparative study on pollution-block performance of ceiling-supply air curtain system for commercial building entrance
}

\author{
Ran Duan ${ }^{1}$, Jiagen Liu $^{2}$ \\ ${ }^{1}$ THUPDI, Beijing, China \\ ${ }^{2}$ THAD, Beijing, China
}

\begin{abstract}
Air curtain is often used as a dynamic barrier to separate indoor and outdoor environments. This investigation evaluated the pollution-block performance of ceilingsupply air curtain system with varying air supply angles, volume flow rates, and velocities, using a validated computation fluid dynamics (CFD) model. The study found that the pollution-block performance of different air supply angles of air curtain was related with air supply velocity. The study predicted that with a constant air supply velocity, varying air supply volume flow rate had little impact on preventing outdoor pollution entering the building. For ceiling-supply air curtain, the recommended air supply velocity should be large enough to ensure the supply air to strike the floor before it is blown away by the outdoor wind at the entrance.
\end{abstract}

\section{Introduction}

Outdoor particulate matter (PM) pollution is severe in China that is harmful to human health. Particulates can enter building across open door and/or window and worsen indoor air quality. Air curtain is often used as a dynamic barrier to constrain heat and mass transfer between indoor and outdoor environments. Improving the pollution-block effect of air curtain is an important subject for building engineers.

Significant effort has been put recently to investigate and improve air curtain performance by both experimental and simulated studies. For example, Elharriry et al. (2013) demonstrated the importance of air curtains on cold rooms by CFD. Gil-Lopez et al. (2013) analysed energy savings and hydrothermal condition improvements by means of air curtains through experiment. Goubran et al. (2016) presented an experimental study to verify and further investigate the flow characteristics of building entrances equipped with air curtains and found that experiment and simulation provided similar results. Gonçalves et al. (2012) studied the influences of different air curtain locations. However, the existing researches didn't address the effects of different air curtain supply angles, volume flow rates, and velocities.

This investigation evaluated the pollution-block performance of a ceiling-supply air curtain system at a commercial building entrance with varying air supply angles, volume flow rates, and velocities, using a validated computation fluid dynamics (CFD) model. The goal was to identify a suitable air curtain design in order to block mass and heat transfer (particularly PM2.5) from the outdoor environment.

\section{Methods}

CFD technique has been widely used to analyse the mass and heat transfer of air curtain. An unstructured mesh was adopted for the spatial discretization of the domain, Tests were conducted to verify the independence of the results with mesh size. The total grid number of grids is about 0.5 million. Many researches (e.g., Maxwell et al., 2016; Wang and Zhong, 2014) commonly used the standard k- $\varepsilon$ model. This research used commercial CFD software, FLUENT (ANSYS Inc., 2011) for the numerical simulations. The software employs the SIMPLE (Patankar, 1980) algorithm to couple the pressure and velocity calculation. The study considered the solutions to be converged when the sum of the normalized residuals for all the cells satisfied the conditions (less than $10^{-6}$ for energy and $10^{-3}$ for all other variables). The normalized residuals were defined as:

$$
R_{\phi}=\frac{\sum_{\text {cellsP }}\left|\sum_{n b} a_{n b} \phi_{n b}+b-a_{P} \phi_{P}\right|}{\sum_{\text {cellsP }}\left|a_{P} \phi_{P}\right|}
$$

where $\phi_{P}$ and $\phi_{n b}$ are the variable of the present and neighbouring cells, respectively; ${ }_{P}$ is the coefficient of the variable at the present cell; $a_{n b}$ are the correlation coefficients of the variable of the neighbouring cells; and $\mathrm{b}$ is the source term or boundary conditions.

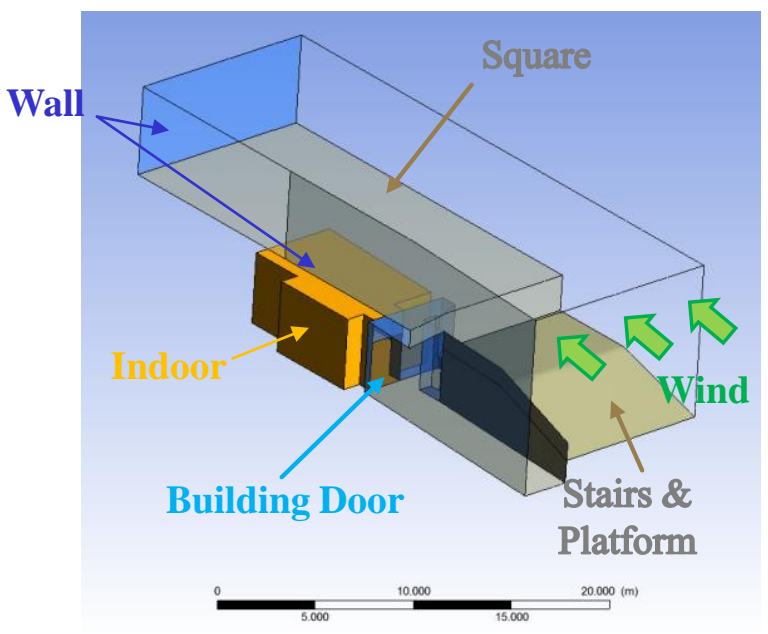


(a) Computation domain

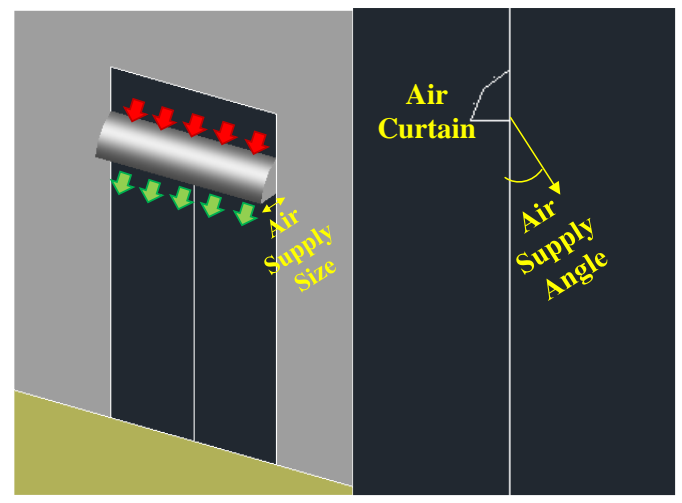

(b) Air curtain

Figure 1: Computational domain and air curtain model.

Figure 1(a) shows the CFD computational domain. The outdoor PM2.5 concentration is set at $500 \mu \mathrm{g} / \mathrm{m}^{3}$. Outdoor wind could enter the building through the entrance when the door is open. The wind direction isshown in the Fig.1(a).. The wall boundaries are shown in Fig. 1(a) and the others are outflow, such as top and other side boundaries. Ceiling-supply air curtain is installed above the door. Figure 1(b) shows the ceiling-supply air curtain. The air curtain parameters tested for all the cases are listed in Table 1. A case without air curtain (Case A in Table 1) was also modelled for comparison. Volume flow rate can be an important factor in blocking the wind. Both air supply velocity and supply size influence the volume flow rate. This research chose 3 different air supply sizes with same supply velocity for comparison. Further, this study tested 3 different air supply velocities to analyse the influence of velocity. Air supply angle of air curtain also influences the pollution-block performance of air curtain. Small and large air supply velocities were tested with 4 air supply angles, respectively.

Table 1: Tested cases with various design parameters of air curtain.

\begin{tabular}{|c|c|c|c|}
\hline Case & $\begin{array}{c}\text { Air Supply Size } \\
(\mathbf{m m})\end{array}$ & $\begin{array}{c}\text { Velocity } \\
(\mathbf{m} / \mathbf{s})\end{array}$ & $\begin{array}{c}\text { Angle } \\
\left({ }^{\circ}\right)\end{array}$ \\
\hline A & NA & NA & NA \\
\hline B & 200 & 5 & 0 \\
\hline C & 400 & 5 & 0 \\
\hline D & 600 & 5 & 0 \\
\hline E & 200 & 2.5 & 0 \\
\hline F & 200 & 10 & 0 \\
\hline G & 200 & 5 & 30 \\
\hline H & 200 & 5 & 45 \\
\hline I & 200 & 5 & 60 \\
\hline J & 200 & 5 & 75 \\
\hline K & 200 & 10 & 15 \\
\hline L & 200 & 10 & 30 \\
\hline M & 200 & 10 & 45 \\
\hline
\end{tabular}

\begin{tabular}{|l|l|l|l|}
\hline $\mathrm{N}$ & 200 & 10 & 60 \\
\hline
\end{tabular}

\section{Results}

Comparison between experimental data and CFD results

The study first conducted a field test with a portable anemometer on the outdoor wind condition and the associated air velocity at the entrance when the door was open. The measured outdoor wind condition was used as the inlet boundary condition. Figure 2 shows the test points at the entrance. Figure 3 presents the comparison of the measured and simulated velocities at the entrance. The comparison reveals a good match between the experiment and prediction, validating the CFD model. The validated model was then used for the parametric studies.

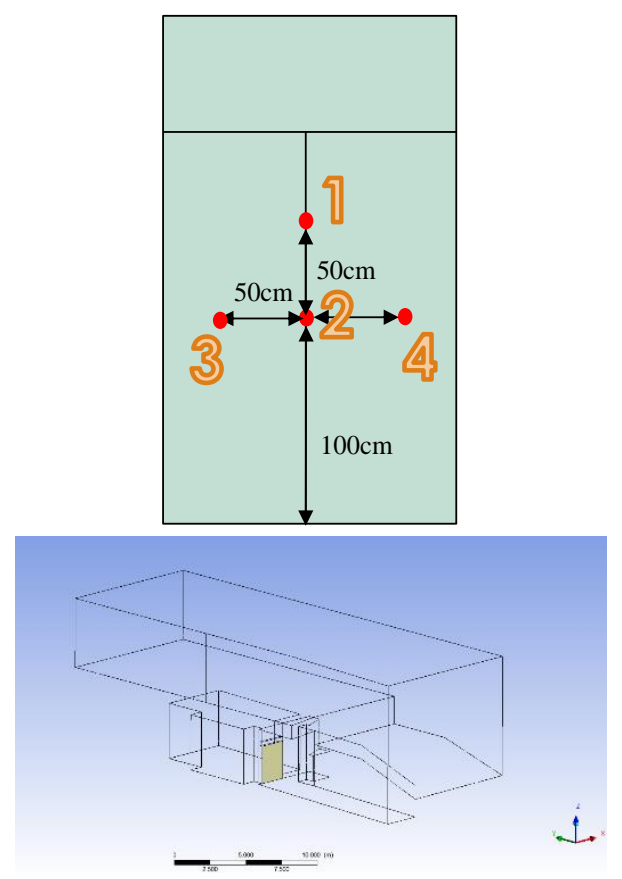

Figure 2: Test points at the entrance.

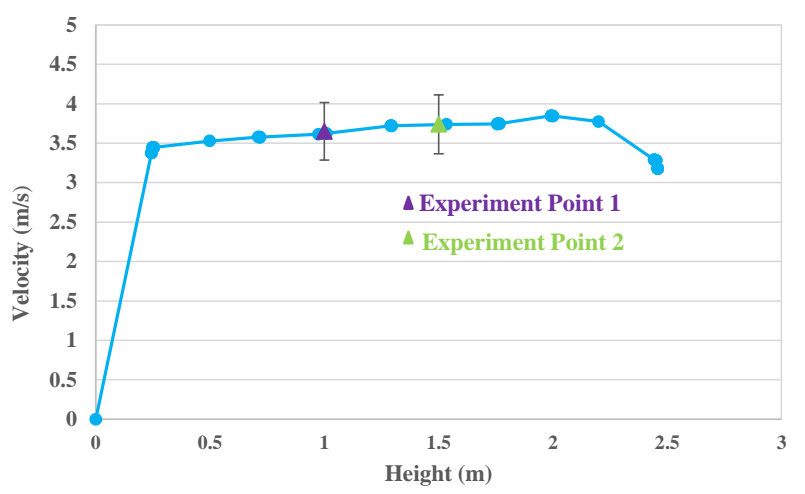

(a) Vertical line 


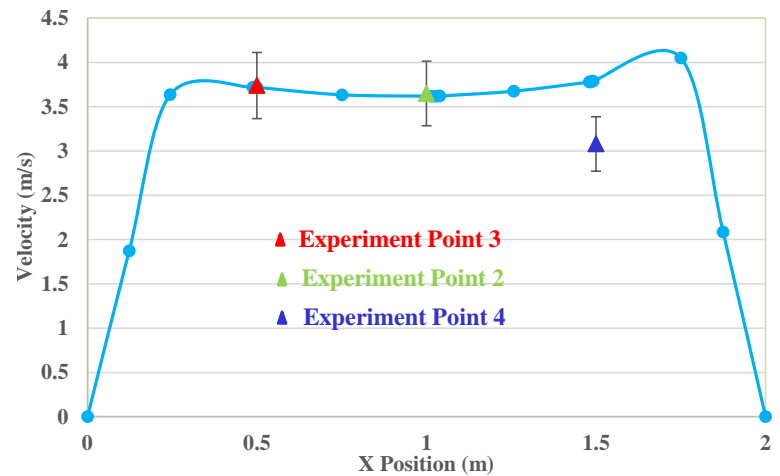

(b) Horizon line

Figure 3: Comparison of measured and simulated velocities at the entrance.

\section{Comparison of indoor pollution with and without air curtain at the entrance}

The simulation results reveal that an open building entrance leads to a large number of particulates flowing into the space. The air curtain may partly separate indoor and outdoor air environments, thus reducing the indoor PM2.5 concentration (Figure 4).

\section{Mass Fraction}

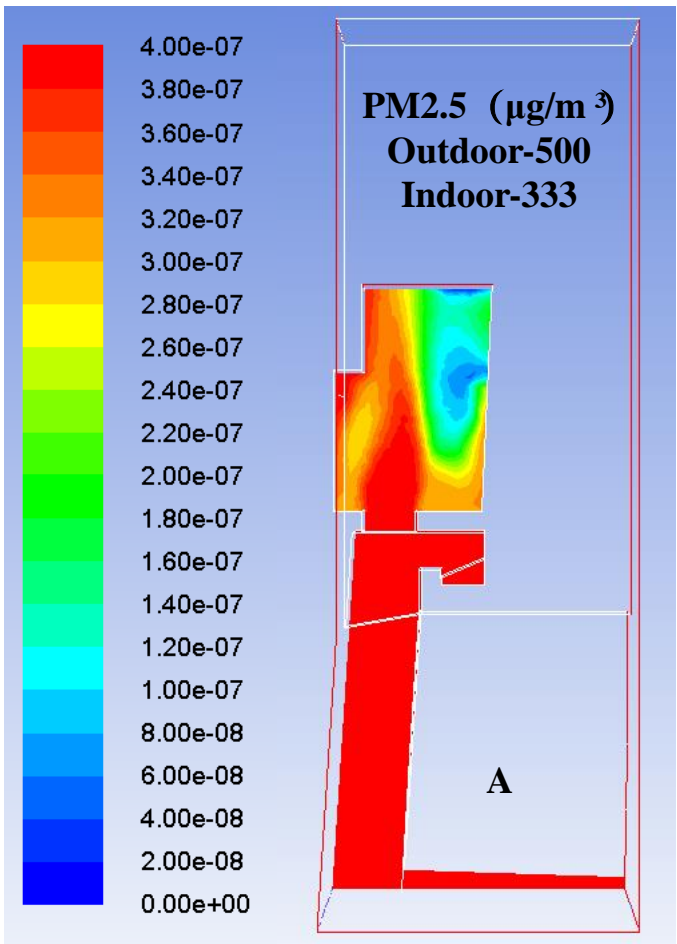

(a) Case A-Without air curtain

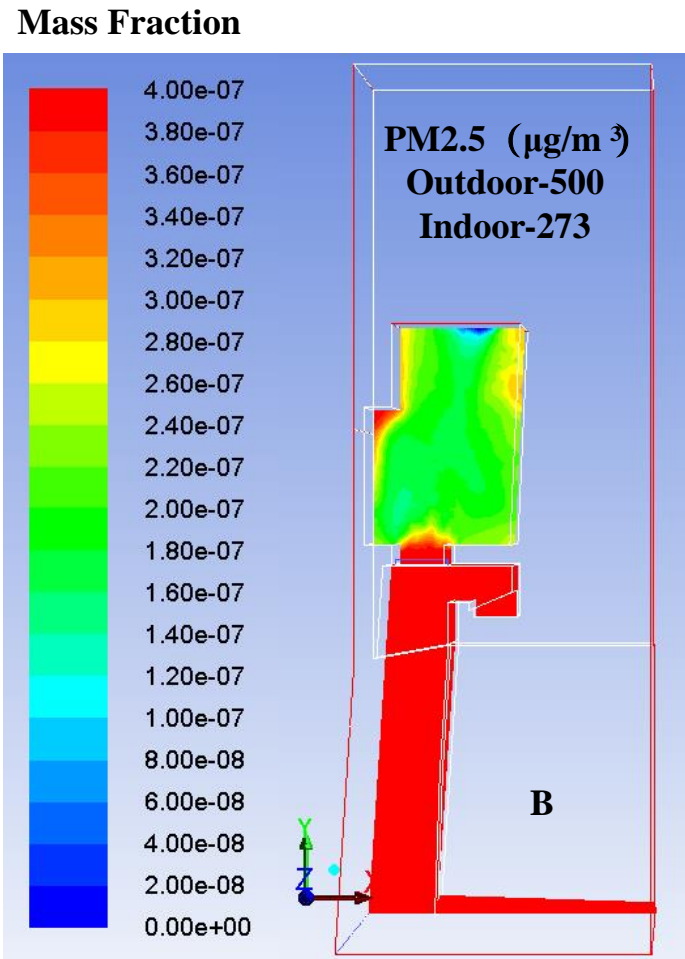

(b) Case B-With air curtain

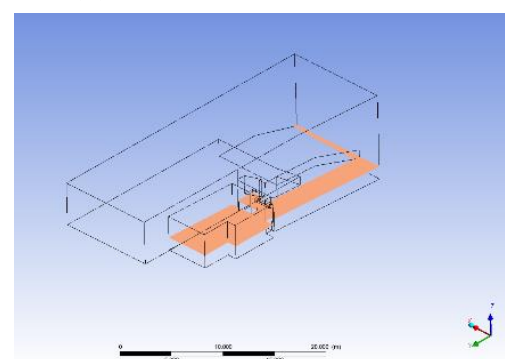

Figure 4: Comparison of the PM2.5 concentration simulated with /without air curtain at $z=1.5 \mathrm{~m}$.

Influences of supply flow rates of air curtain

The study predicted that with a constant air supply velocity of air curtain, varying air supply volume flow rate had some impact on preventing outdoor pollution from entering the building (Figure 5). However, this influence was not proportional to the increase of the supply volume rate (Table 2). In other words, increasing supply air flow rate is not an effective way to protect indoor environments. 


\section{Mass Fraction}

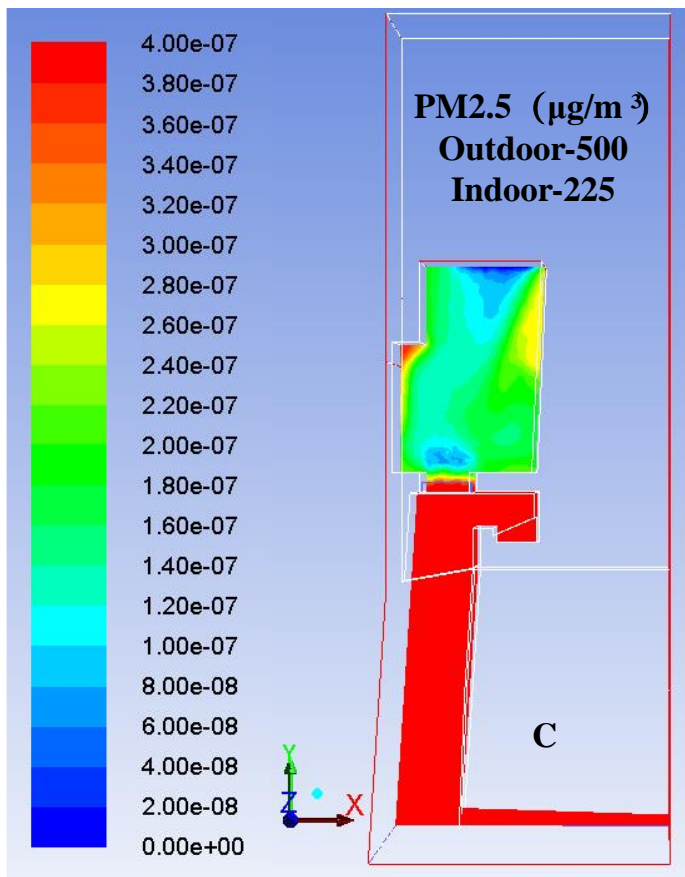

(a) Air supply size-400mm

Mass Fraction

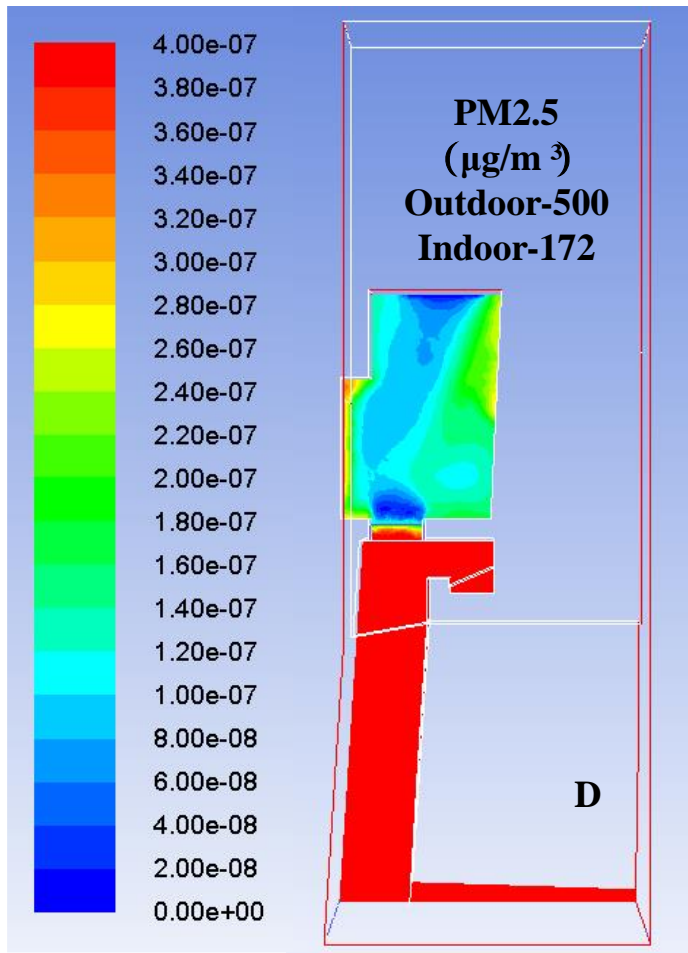

(b) Air supply size-600mm

Figure 5:. Comparison of the PM2.5 concentration simulated with different supply flow rates at $z=1.5 \mathrm{~m}$.

Table 2: Indoor PM2.5 with different supply flow rates.

\begin{tabular}{|c|c|c|c|c|}
\hline & $\begin{array}{c}\text { Air Supply Size } \\
(\mathrm{mm})\end{array}$ & $\begin{array}{c}\text { Velocity } \\
(\mathrm{m} / \mathrm{s})\end{array}$ & $\begin{array}{c}\text { Angle } \\
\left({ }^{\circ}\right)\end{array}$ & $\begin{array}{c}\text { PM2.5 } \\
\left(\mu \mathrm{g} / \mathrm{m}^{3}\right)\end{array}$ \\
\hline A & NA & NA & NA & 333 \\
\hline B & 200 & 5 & 0 & 273 \\
\hline
\end{tabular}

\begin{tabular}{|l|l|l|l|l|}
\hline $\mathrm{C}$ & 400 & 5 & 0 & 225 \\
\hline $\mathrm{D}$ & 600 & 5 & 0 & 172 \\
\hline
\end{tabular}

\section{Influences of supply flow velocities of air curtain}

Figure 6 and Table 3 show the predictions with the same air supply size but diifferent air supply velocities. Increasing supply air velocity obviously improves the system performance. Comparing Case $\mathrm{C}$ and Case $\mathrm{F}$ that had the same air supply flow rates shows that Case F had a lower indoor PM2.5 concentration. It appears that air supply velocity of air curtain has more significant impact on the pollution-block outcome. For ceiling-supply air curtain, the recommended air supply velocity should be large enough to ensure the supply air to strike the floor before it is blown away by the outdoor wind at the entrance.

\section{Mass Fraction}

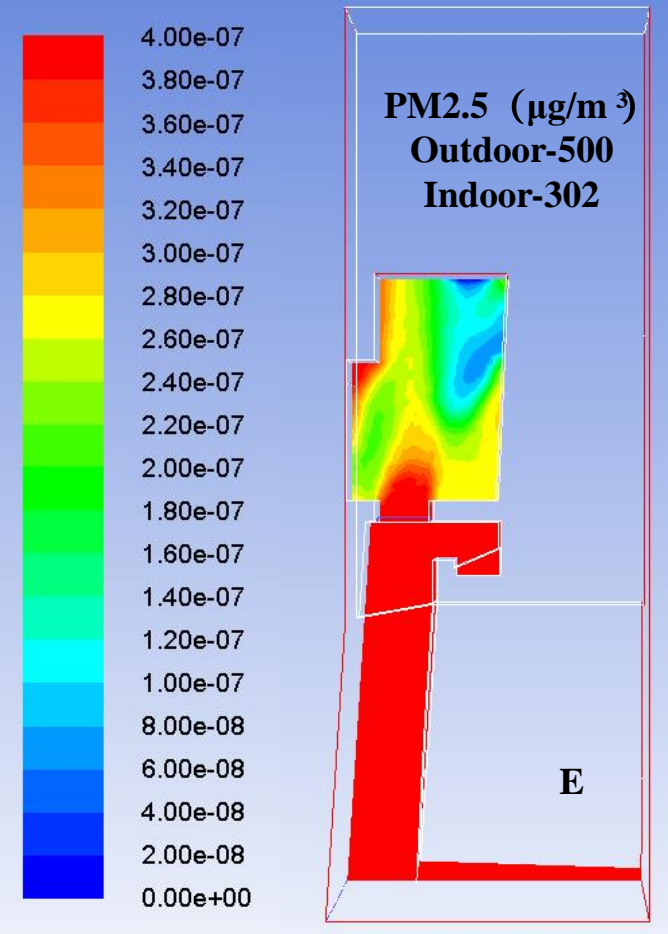

(a) Air supply velocity- $2.5 \mathrm{~m} / \mathrm{s}$ 


\section{Mass Fraction}

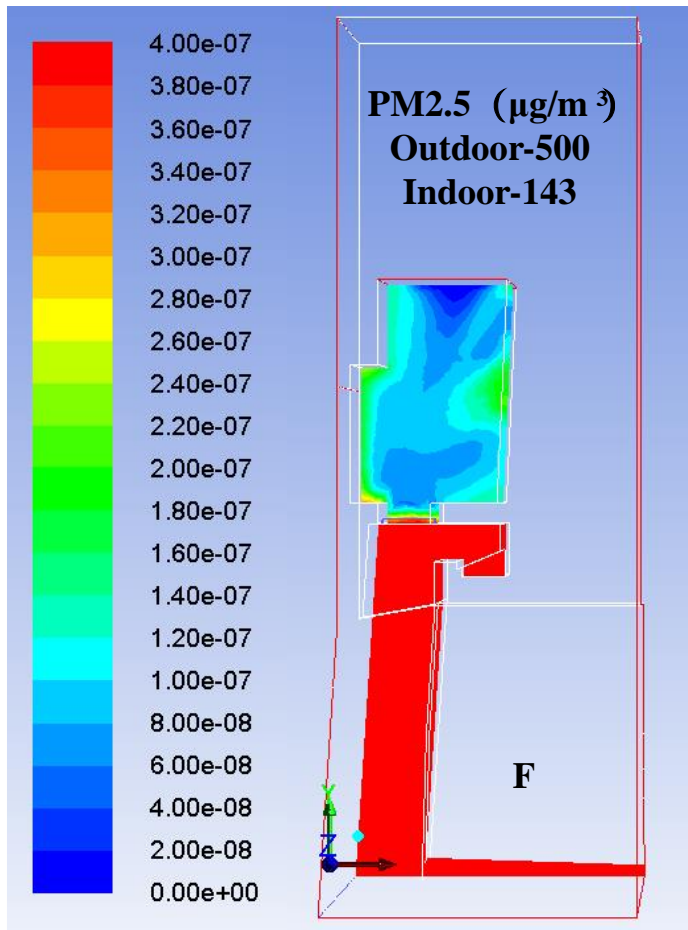

(b) Air supply velocity-10m/s

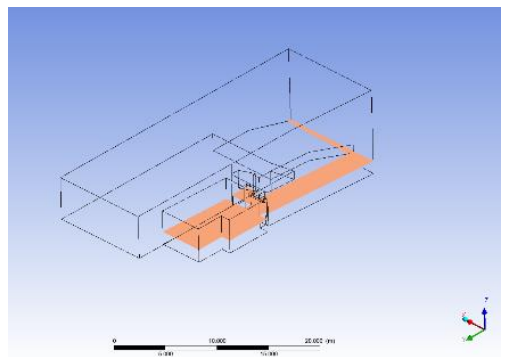

Figure 6: Comparison of the PM2.5 concentration simulated with different supply flow velocities at $z=1.5 \mathrm{~m}$

Table 3: Indoor PM2.5 with different supply velocities.

\begin{tabular}{|c|c|c|c|c|}
\hline & $\begin{array}{c}\text { Air Supply Size } \\
(\mathrm{mm})\end{array}$ & $\begin{array}{c}\text { Velocity } \\
(\mathrm{m} / \mathrm{s})\end{array}$ & $\begin{array}{c}\text { Angle } \\
\left({ }^{\circ}\right)\end{array}$ & $\begin{array}{c}\text { PM2.5 } \\
\left(\mu \mathrm{g} / \mathrm{m}^{3}\right)\end{array}$ \\
\hline A & NA & NA & NA & 333 \\
\hline B & 200 & 5 & 0 & 273 \\
\hline E & 200 & 2.5 & 0 & 302 \\
\hline F & 200 & 10 & 0 & 143 \\
\hline
\end{tabular}

\section{Influences of supply angles of air curtain}

Adjusting air supply angle can be an effective solution to block outdoor pollutant. Figure 7 and 8 show the airflow patterns simulated with different supply angles at the middle section of the door when supply air velocity is $5 \mathrm{~m} / \mathrm{s}$ (small) and $10 \mathrm{~m} / \mathrm{s}$ (large), respectively. Table 4 and 5 detail the indoor PM2.5 concentrations of these cases.

When air supply velocity (supply flow rate) of air curtain is small, outdoor wind alters air curtain airflow direction and pushs the supply air towards indoor. Larger air supply angle can overcome the horizontal wind impact and enforce the curtain airflow direction to be close to the vertical direction as originally planned. As a result, large air supply angle can help achieve a low indoor pollution concentration. However, if the air supply angle is more than $60^{\circ}$, the air flow direction is over-corrected and will be towards outdoor so the oudtoor pollutant can enter the building from two sides of the air curtain that results in a worse indoor environment. It was noted that even if the supply angle was increased, the small air supply velocity had worse performance to block pollutants than the large air supply velocity. This comfirms the important role of supply air velocity.
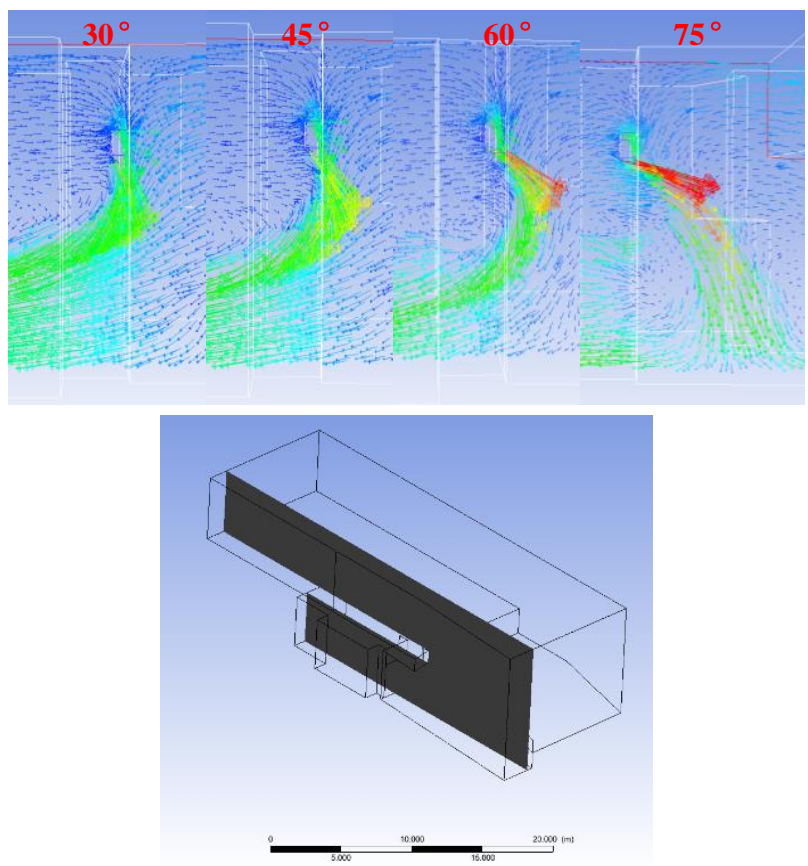

Figure 7: Comparison of the airflow patterns simulated with different supply angles at the middle section of the door when supply air velocity is $5 \mathrm{~m} / \mathrm{s}$.

Table 4: Indoor PM2.5 with different supply angles with small supply velocity.

\begin{tabular}{|c|c|c|c|c|}
\hline & $\begin{array}{c}\text { Air Supply Size } \\
(\mathrm{mm})\end{array}$ & $\begin{array}{c}\text { Velocity } \\
(\mathrm{m} / \mathrm{s})\end{array}$ & $\begin{array}{c}\text { Angle } \\
\left({ }^{\circ}\right)\end{array}$ & $\begin{array}{c}\text { PM2.5 } \\
\left(\mu \mathrm{g} / \mathrm{m}^{3}\right)\end{array}$ \\
\hline A & NA & NA & NA & 333 \\
\hline B & 200 & 5 & 0 & 273 \\
\hline G & 200 & 5 & 30 & 247 \\
\hline H & 200 & 5 & 45 & 241 \\
\hline I & 200 & 5 & 60 & 189 \\
\hline J & 200 & 5 & 75 & 262 \\
\hline
\end{tabular}

When air supply velocity (supply flow rate) is large, the influence of outdoor wind on the air flow direction decreases. When the air supply angle is less than $30^{\circ}$, the air flow direction is towards indoor. When the air supply angle is about $30^{\circ}$, the airflow direction is close to the vertical direction in which the air curtain has good pollution-block performance. When the air supply angle is more than $30^{\circ}$, the air flow direction is towards outdoor. 

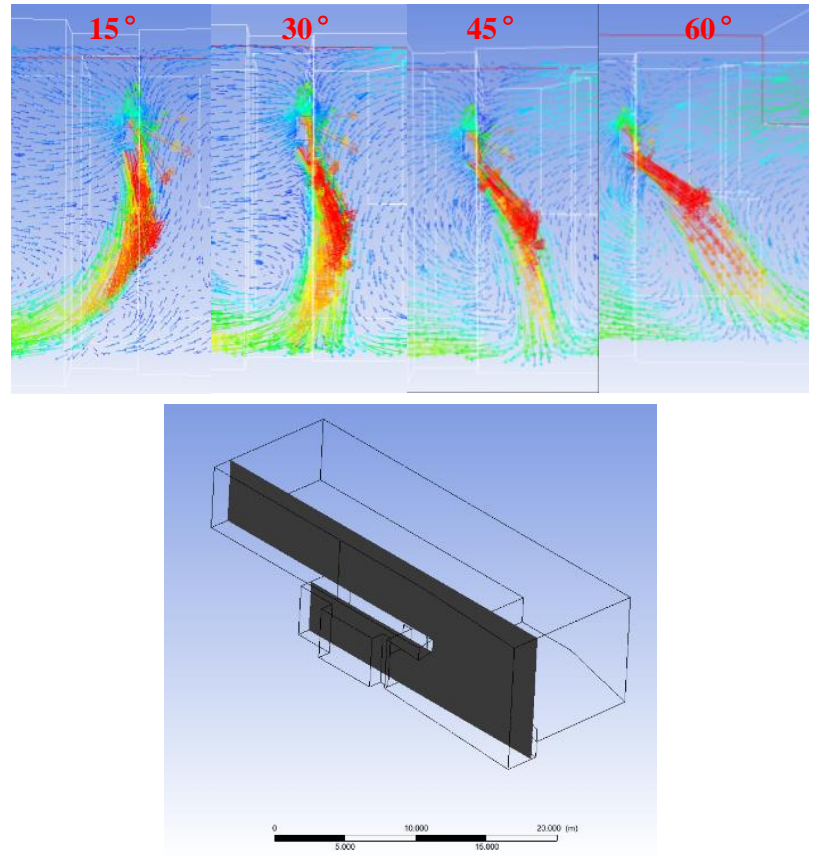

Figure 8: Comparison of the airflow patterns simulated with different supply angles at the middle section of the door when supply air velocity is $10 \mathrm{~m} / \mathrm{s}$.

Table 5: Indoor PM2.5 with different supply angles with large supply velocity.

\begin{tabular}{|c|c|c|c|c|}
\hline & $\begin{array}{c}\text { Air Supply Size } \\
(\mathrm{mm})\end{array}$ & $\begin{array}{c}\text { Velocity } \\
(\mathrm{m} / \mathrm{s})\end{array}$ & $\begin{array}{c}\text { Angle } \\
\left({ }^{\circ}\right)\end{array}$ & $\begin{array}{c}\text { PM2.5 } \\
\left(\mu \mathrm{g} / \mathrm{m}^{3}\right)\end{array}$ \\
\hline A & NA & NA & NA & 333 \\
\hline F & 200 & 10 & 0 & 143 \\
\hline K & 200 & 10 & 15 & 66 \\
\hline L & 200 & 10 & 30 & 53 \\
\hline M & 200 & 10 & 45 & 55 \\
\hline N & 200 & 10 & 60 & 245 \\
\hline
\end{tabular}

This study found that the pollution-block performance of different air supply angles of air curtain was related with air supply velocity. Small air supply velocity requires a relatively large air supply angle to achieve a lower indoor pollution concentration, while large air supply velocity requires a smaller air supply angle.

The simulation results reveal that an open building entrance leads to a large number of particulates flowing into the space and air curtain may partly separate indoor and outdoor air environments. This study found that the pollution-block performance of different air supply angles of air curtain was related with air supply velocity. Small air supply velocity requires a relatively large air supply angle to achieve a lower indoor pollution concentration, while large air supply velocity requires a smaller air supply angle. This can be explained using the pressure balance theory caused by the supply air and the outdoor wind at the entrance. The study predicted that with a constant air supply velocity of air curtain, varying air supply volume flow rate had little impact on preventing outdoor pollution from entering the building. Among various parameters tested, air supply velocity of air curtain has the most significant influence on the pollutionblock performance. For ceiling-supply air curtain, the recommended air supply velocity should be large enough to have the airflow from the air curtain to reach the floor before it is blown away by the outdoor wind at the entrance.

\section{Conclusions}

The simulation results reveal that an open building entrance leads to a large number of particulates flowing into the space and air curtain may partly separate indoor and outdoor air environments. This study found that the pollution-block performance of different air supply angles of air curtain was related with air supply velocity. Small air supply velocity requires a relatively large air supply angle to achieve a lower indoor pollution concentration, while large air supply velocity requires a smaller air supply angle. This can be explained using the pressure balance theory caused by the supply air and the outdoor wind at the entrance. The study predicted that with a constant air supply velocity of air curtain, varying air supply volume flow rate had little impact on preventing outdoor pollution from entering the building. Among various parameters tested, air supply velocity of air curtain has the most significant influence on the pollutionblock performance. For ceiling-supply air curtain, the recommended air supply velocity should be large enough to have the airflow from the air curtain to reach the floor before it is blown away by the outdoor wind at the entrance.

\section{References}

ANSYS Inc.. 2011. ANSYS Fluent 14.0 user's guide. ANSYS Inc. Southpointe.

Elharriry, G., Zeid, A. A., \& Khalil, E. 2013. An investigation of Air Curtains Flows Effects on heat and mass transfer Characteristics in a cold room. Aiaa/asme/sae/asee Joint Propulsion Conference \& Exhibit.

Gil-Lopez, T., Galvez-Huerta, M. A., Castejon-Navas, J., \& Gomez-Garcia, V. 2013. Experimental analysis of energy savings and hygrothermal conditions improvement by means of air curtains in stores with intensive pedestrian traffic. Energy \& Buildings, 67(4), 608-615.

Gonçalves, J. C., Costa, J. J., Figueiredo, A. R., \& Lopes, A. M. G. 2012. CFD modelling of aerodynamic sealing by vertical and horizontal air curtains. Energy \& Buildings, 52(3), 153-160.

Goubran, S., Qi, D., Saleh, W. F., Wang, L., \& Zmeureanu, R. 2016. Experimental study on the flow characteristics of air curtains at building entrances. Building \& Environment, Vol.105, pp. 225-235. 
Maxwell, P., Durrani, F., \& Eftekhari, M. 2016. Investigating heat loss through vestibule doors for a non-residential building. Sustainability in Environment, 1, 25-39.

Wang L. (Leon) and Zhong Z. 2014. Whole building annual energy analysis of air curtain performance in commercial building, in: eSim.

Patankar S. 1980. Numerical heat transfer and fluid flow. Washington Dc Hemisphere Publishing Corp.p, 27(1), 125-12. 